\section{WORKSITE HEALTH PROMOTION PROGRAMME FOR WOMEN}

Gurjeet Kaur Chawla, G L Khanna Manav Rachna International University, Faridabad, Harayana, India

10.1136/bjsm.2010.078725.252
A healthy motivated workforce is very vital to an organisation. All over the world various organisations are investing on employees healthcare as health hazards exposure among employees for long are reflected on financial and goodwill status. Organisations that are implementing worksite health promotion programme and strategies achieve reduction in healthcare cost and long term disability along with additional benefits including reduced absenteeism, higher productivity and increased loyalty among employees. But it is an irony of fate that health hazards of women workers have been underestimated because occupational safety and health standards as well as exposure limits to hazardous substances are not based on female population. These factors contribute to work injuries, illnesses, physical stress and hypertension causing deterioration in the health of women workers leading to fatalities. It is amply manifest and greatly emphasised that worksite conditions of working women particularly in industries need to pay greater attention as women face a wide range of health and nutrition related problems throughout the life cycle. Women's safety and health problems are frequently ignored or are not accurately reflected in research and data collection.

If health promotion policies are to be effective for women, they must be based on more accurate information about the relationship between health and gender roles. Health promotion programmes or policies for working women need to take into account manifold functions of their lives. Measures should be taken to control occupational hazards to which women workers are exposed. Special action programme should be developed for work related hazards within each occupation, including psycho-social and organisational factors, taking into consideration the physical, mental and social wellbeing of women workers to get better productivity at workplace as well as to enjoy the given work activities to maintain balanced health and attribute wealth to the country. 